\title{
Microbiological Quality of Hoplobatrachus occipitalis (Amphibia, Anura) Used as Meat
}

\author{
Douglas, Salome Ibietela ${ }^{1^{*}}$ and C.C. Amuzie ${ }^{2}$ \\ ${ }^{1}$ Department of Microbiology, Rivers State University of Science and Technology, \\ Port Harcourt, Nigeria \\ ${ }^{2}$ Department of Animal and Environmental Biology, Rivers State University of Science and \\ Technology, Port Harcourt, Nigeria \\ *Corresponding author
}

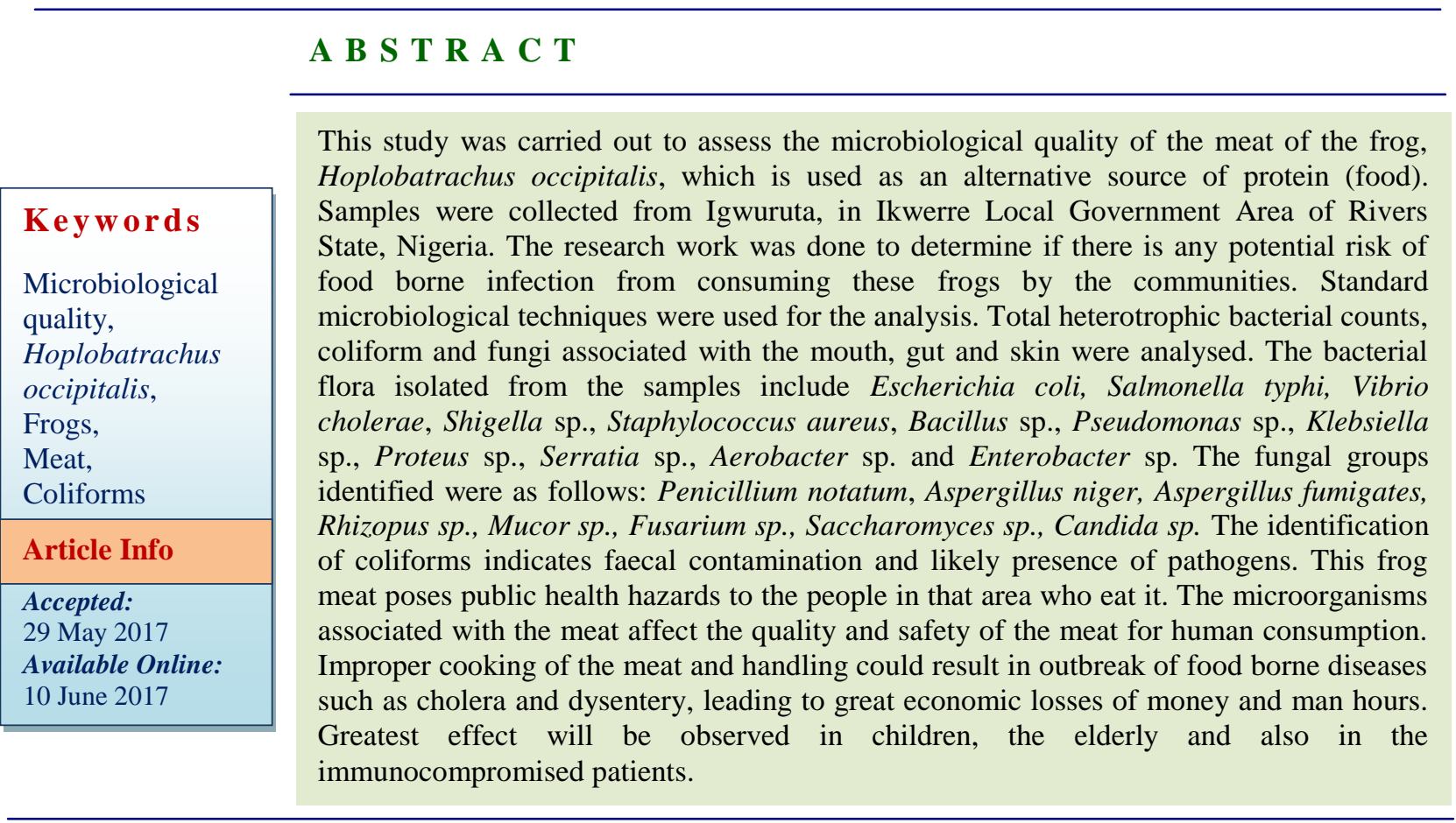

\section{Introduction}

The anurans, also commonly called frogs or toads are amphibians. Their meat is becoming popular as a source of protein in many countries including Nigeria (Ondeko et al., 2011). They are reared commercially in countries like Malaysia, Taiwan, Indonesia, Brazil and Mexico for human consumption, while others such as USA, France, Canada, Belgium, Italy and Spain are the major importers of frog meat (Ho et al., 2008; Baygar and Ozyur, 2010). In most of these countries, the frog legs (the meaty hind legs) likened to that of a small chicken drumstick, are the main parts consumed, believed to be a delicacy. These organisms are consumed in large amounts in European countries. High consumption rates were reported in Italian and French restaurants and in holiday villages 
in Turkey (Baygar and Ozyur, 2010). Frogs have been used in the production of infant food (Rodrogues et al., 2014). The species mostly imported for consumption were the green frog (Rana clamitans), leopard frog (R. pipiens) and the bullfrog ( $R$. catesbeiana) (Helfrich et al., 2009).

Frog meat is also a delicacy in parts of Rivers State where they are harvested from the forests and temporary ponds in water logged areas; the gut is removed and discarded while the rest of the animal is cooked. All the Ptychadena species are found in Rivers State, which include $P$. mascareniensis, $P$. oxyrhynchus, $P$. pumilio, $P$. bibroni, $P$. schubotzi and P. longirostris and the African bullfrog, $H$. occipitalis, are consumed by the locals in Igwuruta, Rivers State (Amuzie and Akani, 2017 - in press). In parts of Oyo State (Nigeria), similar species are also consumed: the gut is removed; the rest of the frog is pinned to sticks and smoked. These are then sold in their local markets for consumption (Omuguba, personal communication). The meat serves as food as well as a source of income or foreign exchange (Onadeko et al., 2011). This research was undertaken since there is a dearth of information available in this area; most of the work done is on the nutritional composition (Ho et al., 2008; Rodrogues et al., 2014). So, there is need to investigate the microbiological quality due to the increase in consumption rate.

\section{Materials and Methods}

\section{Sample collection}

Live adult samples of Hoplobatrachus occipitalis were captured, using visual and acoustic survey methods, from Igwuruta area (E 455' 57.006', N 7 ${ }^{\circ} 1$ ' 13.692') of Ikwerre Local Government area of Rivers State, Nigeria, and transported to the Microbiology Laboratory of Rivers State University of Science and Technology, Port Harcourt, in sterile containers. The samples were dissected within $24 \mathrm{hr}$ of capture using standard procedures (Amuzie and Aisien, 2017). The guts of the specimens were excised and refrigerated at $4^{\circ} \mathrm{C}$ in the Laboratory until they were required for use. To ensure the identification of isolates from the samples, more frog samples were collected from the same area, thrice at an interval of one month.

\section{Isolation and identification}

The respective differential media were used for the isolation; nutrient agar (NA), MacConkey agar (MCA), Salmonella- shigella agar (SSA), Eosin methylene blue agar (EMBA), Thiosulfate-Citrate-Bile SaltsSucrose (TCBS) agar and Potato dextrose agar (PDA). All media were prepared according to manufacturer's instruction.

\section{Isolation of the Skin organisms}

Using sterile normal saline, the body of each frog was washed thrice; this was done to remove transient organisms. Thereafter, with the aid of a sterile swabbed stick, the dorsal and the ventral surfaces were swabbed over severally. Using a sterile pipette, $2 \mathrm{ml}$ of sterile normal saline was added to each swab stick (Culp et al., 2007). $1 \mathrm{ml}$ of each sample was then transferred to $9 \mathrm{ml}$ of normal saline, which was then serially diluted to $10-5$. Zero point one milliliters $(0.1 \mathrm{ml})$ aliquot of the appropriate dilution was spread on the surface of the agar using sterile hockey stick. Plates were incubated at $37^{\circ} \mathrm{C}$ for 24 to 48 hours.

\section{Isolation of Mouth Organisms}

The mouth was sampled, by opening gently using a sterile forceps and the inside swabbed with a sterile swab stick. Using a sterile pipette, $2 \mathrm{ml}$ of sterile normal saline was added to each swab stick. $1 \mathrm{ml}$ of each inoculum sample was then transferred to $9 \mathrm{ml}$ of normal saline, which was serially diluted to 
10-5. Zero point one milliliters $(0.1 \mathrm{ml})$ aliquot of the appropriate dilution was spread on the surface of agar using sterile hockey stick. Plates were incubated at $37^{\circ} \mathrm{C}$ for 24 to 48 hours.

\section{Isolation of gut organisms}

The gut was maserated together. Then $1 \mathrm{~g}$ of the maserated internal content was weighed and added to $9 \mathrm{ml}$ of normal saline, shaking vigorously to mix and serially diluted to 10-6. A volume of $0.1 \mathrm{ml}$ was dispensed from $10-4$ to 10-6 dilution tubes, onto the surface of the dried agar plates mentioned above. Fungal counts were done using Potato dextrose agar (supplemented with $0.5 \mathrm{~g} / 1$ chloramphenicol), while the other media were used for the isolation of coliforms and other enteric bacteria (Ogbalu and Douglas, 2015, 2016).

\section{Biochemical characterization of bacteria and fungi}

The colonies that developed on the respective agar plates were counted and subcultured on the respective freshly prepared plates until pure isolates were gotten. Pure isolates were stored on nutrient agar slants and refrigerated at $40 \mathrm{C}$ until required for further use. Further identification was done based on the cultural, morphological, biochemical and Gram's reaction according to Bergey's Manual of Determinative Bacteriology (Holt et al., 1994). While fungi were identified based on their microscopic characteristics (Larone, 1995; Barnett and Hunter, 1972).

\section{Statistical analysis}

Group average cluster analysis was used to test for significant differences between the microbial counts obtained from the various culture media after the counts were converted to $\log$ to base ten and Bray-Curtis resemblance computed. SIMPROF tests were used to test for the statistical significance of the cluster analysis. Statistical analysis was carried out using PRIMER-v7.

\section{Results and Discussion}

Results of the investigation indicated that all samples analyzed had varying degrees of microbial load. Total heterotrophic bacteria counts, coliform and fungi associated with the mouth, gut and skin are displayed in figures 1 - 9. The microflora of the mouth on nutrient agar ranged from $2.8 \times 10^{6}$ to $7.2 \times 10^{6}$ cfu/ml, on Mac Conkey agar(MCA); $1.3 \mathrm{X}$ $10^{5}$ to $5.6 \times 10^{5} \mathrm{cfu} / \mathrm{ml}$ and on Potato dextrose agar(PDA); $2.2 \times 10^{4}$ to $8.7 \times 10^{4}$ $\mathrm{cfu} / \mathrm{ml}$. Gut microflora ranged from $8.1 \times 10^{7}$ to $2.4 \times 10^{8} \mathrm{cfu} / \mathrm{g}$ on nutrient agar, $1.2 \times 10^{6}$ to $5.8 \times 10^{7} \mathrm{cfu} / \mathrm{g}$ on MCA and $3.4 \times 10^{4}$ to $7.7 \times 10^{5} \mathrm{cfu} / \mathrm{g}$, on PDA. Also, the skin flora ranged; $5.3 \times 10^{6}$ to $8.8 \times 10^{6} \mathrm{cfu} / \mathrm{ml}$ on NA, $1.6 \times 10^{5}$ to $6.9 \times 10^{5} \mathrm{cfu} / \mathrm{ml}$ on MCA while on PDA, it ranged $3.0 \times 10^{4}$ to $7.1 \times 10^{4}$ $\mathrm{cfu} / \mathrm{ml}$. Highest growth was observed on nutrient agar for all samples, while the least was observed on PDA. Out of the three parts sampled, the gut had the highest microbial load, while the mouth had the least. The skin harboured greater microbial diversity (Table 1), this may be due to the soil environment were these organisms are found. The bacterial flora isolated from the samples included Escherichia coli, Salmonella typhi, Vibrio cholerae, Shigella sp., Staphylococcus aureus, Bacillus sp., Pseudomonas sp., Klebsiella sp., Proteus sp., Serratia sp., Aerobacter sp. and Enterobacter sp. The fungi identified were as follows: Penicillium notatum, Aspergillus niger, Aspergillus fumigates, Rhizopus sp., Mucor sp., Fusarium sp., Saccharomyces sp. and Candida sp. (Table 1). Bacterial isolates identified were members of both the Gram positive and Gram negative groups, which were also common flora/ inhabitants of the soil and water environments. However, more Gram negative 
bacteria were isolated from the frog than gram positive bacteria. This observation was also made by Culp et al., (2007) who isolated more Gram negative than Gram positive bacteria. Culp et al., (2007) also identified the following organisms on the skin of three frog species: Raoultella terrigena, Agrohactcrium radiohacter, Flavimonas oryzihabitans, Chnjseomonas luteola, Aeromonas hydrophila, Pseudomonas fluorescens, Staphylococcus epidermidis, Microbacterium laevaniformans, Corynebacterium sp, Microbacterium testaceum, Candida molishiana, Flavobacterium johnsoniae, Bacillus cereus. In this study the following were also identified: Aerobacter sp., Pseudomonas sp., Staphylococcus sp., Candida sp., and Bacillus sp.

The cluster analysis and SIMPROF tests revealed highly significant differences in the microbial counts obtained from the various culture media used $(\mathrm{Pi}=2.67 ; \mathrm{P}=0.1 \%)$. This is presented as Figure 10 (The dark lines show samples that are significantly different whereas the red broken lines indicate samples that bear no statistical difference.). The results showed that in the mouth, the counts obtained with MC and EMBA were not statistically different; but the counts obtained with these and the other media were statistically significantly different.

Among the counts obtained from culture of the external surface (or epidermis) of the specimens, those of MC and EMBA were also not significantly different whereas they differed significantly from counts from other media. The situation was somewhat different between the counts obtained from the gut culture. In this case, the counts obtained from four of the media used (EMBA, SSA, TCBS and $\mathrm{MC}$ ) were not significantly different. They were however, significantly different from the counts from PDA and NA. Generally, higher counts were obtained with
NA. This is because NA is a general purpose agar which allows the growth of the various physiological groups present. In the graph (Figure 11), NA counts from the gut of the specimens were significantly different from those obtained from the mouth and external thereby revealing a greater population of microbial forms in the gut of the specimens. These are thought to have been acquired from the organisms, water and debris consumed by the specimens. Similarly, SSA counts of the gut were significantly different from those of the mouth and external samples which did not differ significantly. The same trend was found for PDA and TCBS. However, the counts obtained from MC and EMBA in the gut, mouth and external were not statistically different. These results indicated that the microbial counts from the culture of the mouth and external swab samples of the frog were similar.

In the graph (Figure 11), NA counts from the gut of the specimens were significantly different from those obtained from the mouth and external thereby revealing a greater population of microbial forms in the gut of the specimens. These are thought to have been acquired from the organisms, water and debris consumed by the specimens. Similarly, SSA counts of the gut were significantly different from those of the mouth and external samples which did not differ significantly. The same trend was found for PDA and TCBS. However, the counts obtained from $\mathrm{MC}$ and EMBA in the gut, mouth and external were not statistically different. These results indicated that the microbial counts from the culture of the mouth and external swab samples of the frog were similar. When the months were compared, it was found that the counts obtained from the months of November and December, 2016, did not differ significantly but were significantly different from counts obtained in October, 2016 $(\mathrm{Pi}=0.3 ; \mathrm{P}=0.2 \%)$ (Figure11). This indicates 
seasonal difference, because October, 2016, was part of the rainy season while the dry season commenced in November. Generally, higher counts were obtained in the rainy month of October, 2016, which coincided with a period of higher activity of the host specimens.

Isolation and identification of enteric organisms from the frogs such as E. coli, Salmonella sp., Klebsiella sp., Vibrio sp. and Shigella sp. make the consumption of the meat more worrisome. The presence of $E$. coli, a coliform is a reliable indicator of faecal contamination from warm blooded animals. The coliform, are found in the intestine of warm blooded animals and man as normal flora or commensals which are released out in large numbers during excretion in faeces. When the pathogenic serotype E. coli 0157 gotten from infected frog meat, resulting in colitis with bloody diarrhea is present, it may produce hemolytic uremic syndrome (Ogbalu and Douglas, 2016; Oghene et al., 2014). This pathogenic strain is usually found in the stool of an infected person or animal and person to person transmission could occur through faecal-oral route. The presence of Klebsiella sp. has also been implicated with food poisoning and foodborne illnesses leading to fever, diarrhea, and other symptoms (Ogbalu and Douglas, 2016). The presence of coliforms may be attributed to cattle faeces, since cattle herdsmen regularly brought in cattles to graze in the area and defecation by farmers and others who use the bush as toilet. A strain of Staphylococccus aureus and a species of Bacillus, Bacillus cereus when present in the meat may produce toxin (entertoxin), which is heat stable. These toxins results in food poisoning (gastroenteritis) when consumed. Bacillus sp., is also a normal flora of the soil environment, and able to stay longer in the soil due to its ability to produce endospores, while Staphylococcus aureus is implicated in wound infections (Ogbalu and Douglas, 2016 and 2015). Some species of Pseudomonas (fluorescens) may result in spoilage of food, particularly dairy products and other fat containing foods. Another species, P. aeruginosa is known to be involved in urinary tract infections (Chikere and Azubuike, 2014; Ogbalu and Douglas, 2016). It has also been proved that Pseudomonas sp. adapt to various environmental conditions, using various materials as carbon source, and survive for longer time in the soil environment. It can also be an opportunistic pathogen, in immunecompromised patients (Okechalu et al., 2011; Ogbalu and Douglas, 2016). Enterobacter sp. can be found in water and soil environment, and their presence may be due to faecal contamination, which could result in food poisoning. Some species may be pathogenic, implicated in respiratory tract infection and sometimes may cause septicaemia (Okogbenin et al., 2014).

Table.1 Microbial genera isolated from various parts of the frog

\begin{tabular}{|c|c|}
\hline Frog Part & Organisms Identified \\
\hline Mouth & $\begin{array}{l}\text { Escherichia coli, Salmonella typhi., Bacillus } \mathrm{sp} ., \text { Pseudomonas sp., Serratia sp., Vibrio } \\
\text { cholerae, Enterobacter } \mathrm{sp} ., \text { Staphylococcus aureus, Candida sp., Penicillium sp., } \\
\text { Aspergillus sp., Rhizopus sp., Mucor } \mathrm{sp} ., \text { Fusarium } \mathrm{sp}\end{array}$ \\
\hline Gut & $\begin{array}{l}\text { Proteus sp., Escherichia coli, Vibrio sp., Klebsiella sp., Salmonella typhi., Bacillus sp., } \\
\text { Shigella sp., Staphylococcus sp., Pseudomonas sp., Candida sp., Rhizopus sp., Aspergillus } \\
\text { sp., Penicillium sp. }\end{array}$ \\
\hline Skin & $\begin{array}{l}\text { Bacillus sp., Escherichia coli, Salmonella } \mathrm{sp} ., \text { Klebsiella } \mathrm{sp} ., \text { Vibrio } \mathrm{sp} ., \text { Enterobacter } \mathrm{sp} ., \\
\text { Serratia } \mathrm{sp} ., \text { Pseudomonas } \mathrm{sp} ., \text { Shigella } \mathrm{sp} . \text { Staphylococcus } \mathrm{sp} ., \text { Aerobacter } \mathrm{sp} ., \text { Candida } \\
\text { sp., Penicillium } \mathrm{sp} ., \text { Aspergillus niger, Aspergillus fumigates, Mucor } \mathrm{sp} ., \text { Rhizopus sp., } \\
\text { Saccharomyces sp., Fusarium sp. }\end{array}$ \\
\hline
\end{tabular}


Fig.1 Microbial load on the mouth of samples (October, 2016)

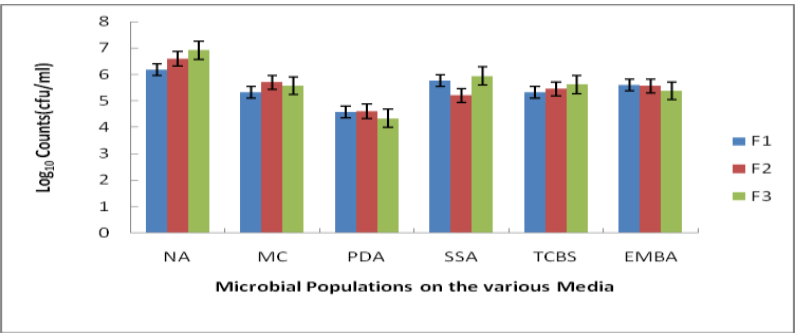

Fig.2 Microbial load in the gut of samples (October, 2016)

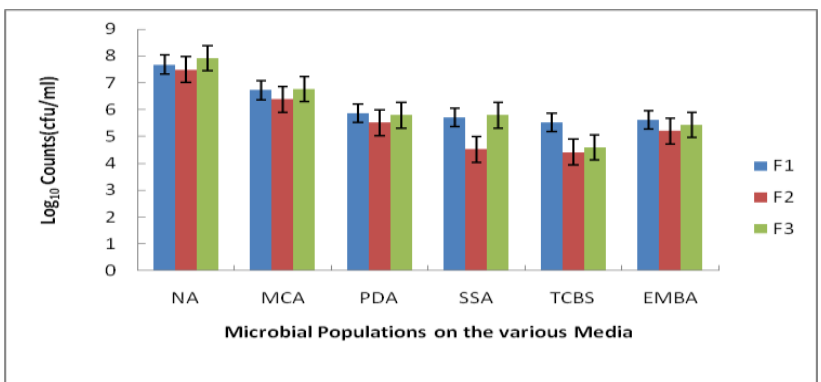

Fig.3 Microbial load on the skin of samples (October, 2016)

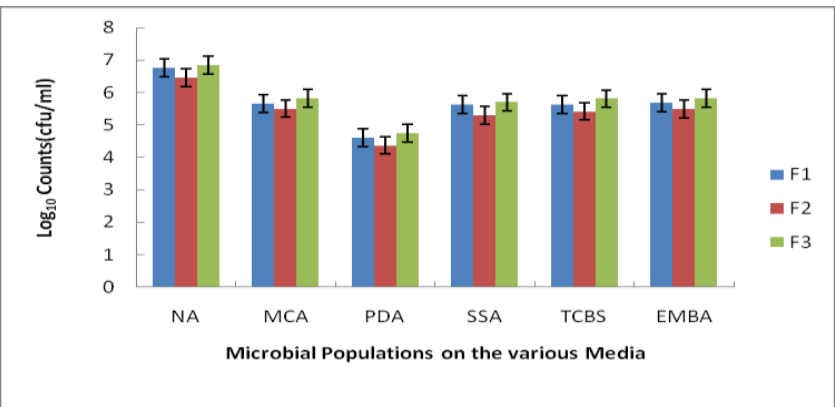

Fig.4 Microbial load in the mouth of samples (November, 2016)

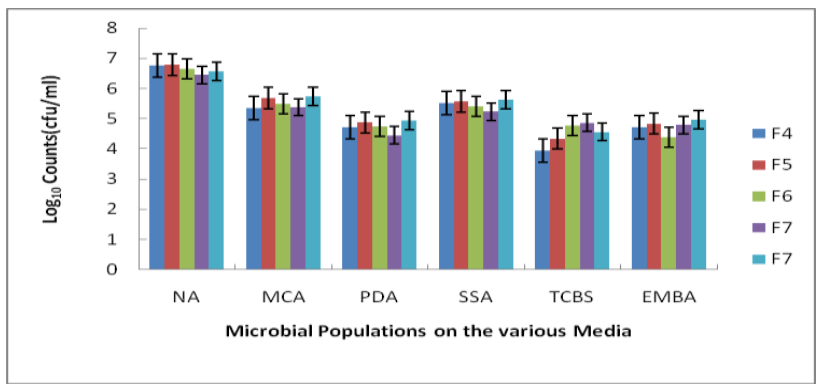

Fig.5 Microbial load in the gut of samples (November, 2016)

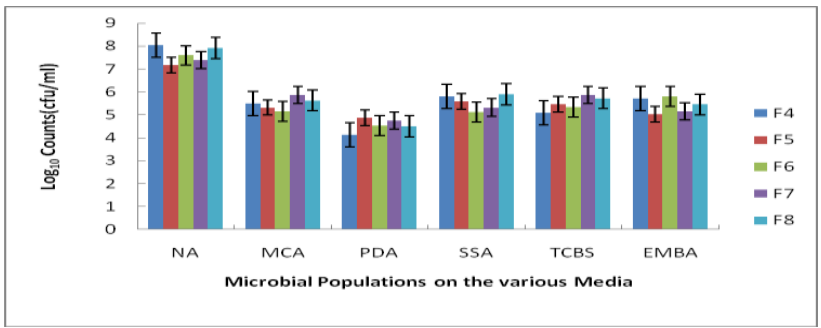


Fig.6 Microbial load on the skin of samples (November, 2016)

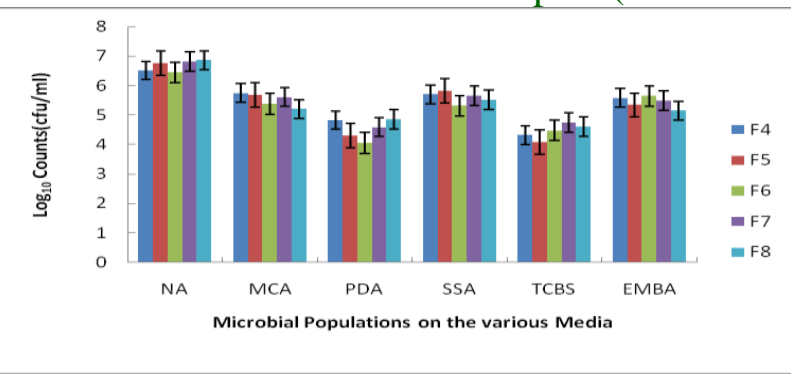

Fig.7 Microbial load in the mouth of samples (December, 2016)

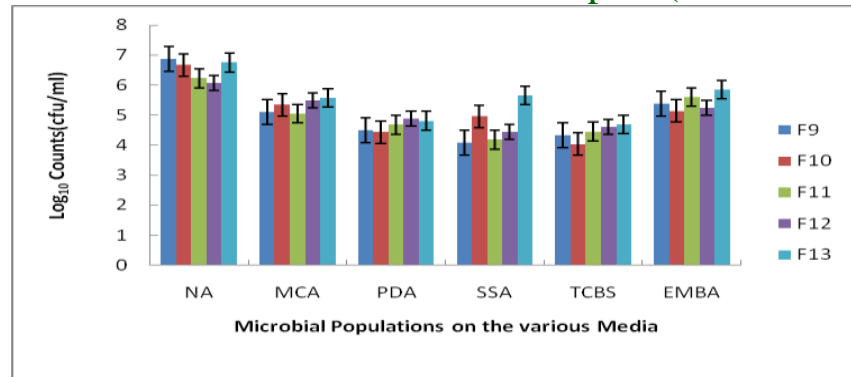

Fig.8 Microbial load in the gut of samples (December, 2016)

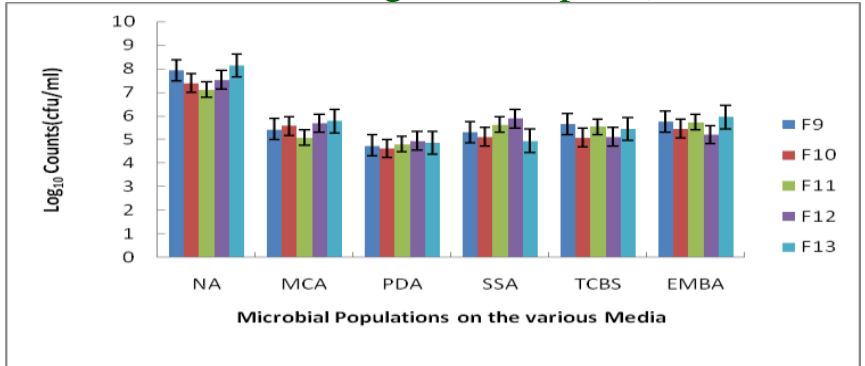

Fig.9 Microbial load on the skin of samples (December, 2016)
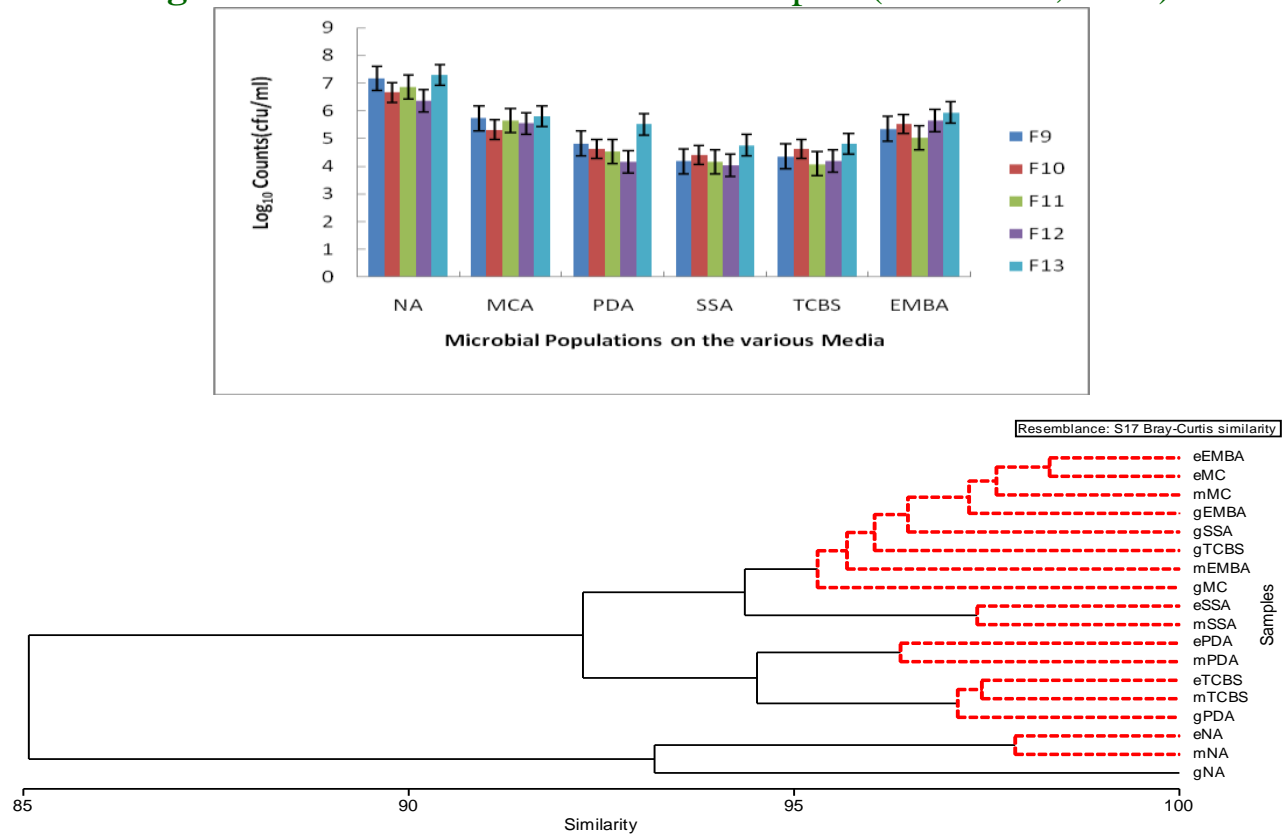

Figure. 10 Group average clustering of the microbial counts obtained from the mouth (m), external (e) and gut (g) of $\mathrm{H}$. occipitalis using various culture media 


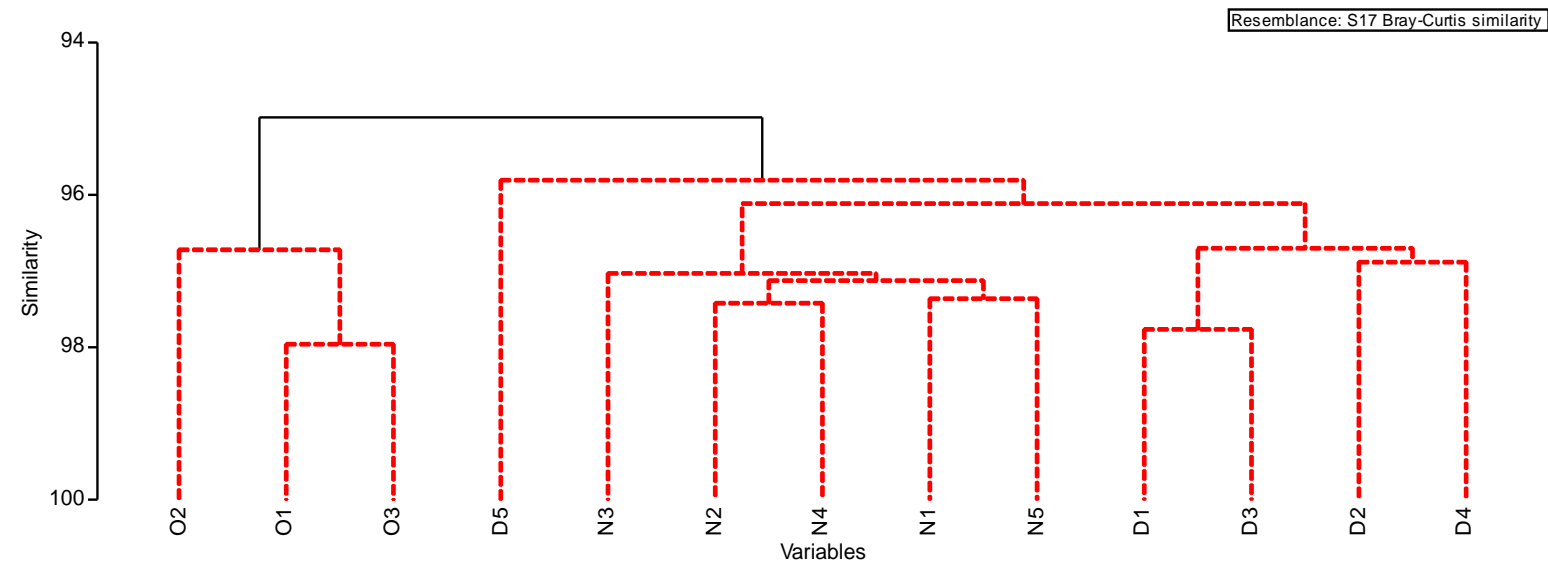

Figure.11 Group average clustering of sampling months, October (O), November (N) and December (D), based on microbial counts obtained from the gut, mouth and external cultures of $\mathrm{H}$. occipitalis

Fungi are known to produce large quantities of spores which enable them to survive in the environment for longer time, even during unfavourable conditions. Some species of Aspergillus when their spores are inhaled may result in Aspergillus-related lungs disease such as allergic alveolitis, asthma, allergic broncho-pulmonary aspergillosis (Chikere and Azubuike, 2014). This organism has also been implicated in man and animal infections which includes: superficial and local infections (cutaneous infections), infections implicated in damaged tissues (aspergilloma). They also produce mycotoxins in human food and animal feed products (Ogbalu and Douglas, 2014). Candida and Aspergillus species have been demonstrated to show great infectivity in various forms of diseases ranging from mucosal to other infections as a result of the activities of the fungal toxins, antigens, or direct invasion of the host tissues (Das, 2013). Research has also indicated that Penicillium sp. are capable of producing toxins called ochratoxin-a, which could cause damage in experimental animals.

The significance of this study, was to assess the microbiological quality(food safety) of this meat. Since, it is becoming very popular among the locals who are consuming it as alternative sources of protein. The microorganisms associated with the meat affect the quality and safety of these organisms for human consumption (Sichewo et al., 2014). The presence of these microorganisms poses public health hazards to the people in that area who consume the frog. Improper cooking of the meat and handling could result in outbreak of food borne diseases such as cholera and dysentery, leading to great economic losses of money and man hours. Greatest effect observed in children, the elderly and also in immunecompromised persons.

In conclusion, this study has revealed the microbial diversity and population associated with frog meat. Assessing the microbial population, diversity and quality of the frog is important, since it is a delicacy. These frogs are susceptible to a wide range of organisms due to their habitat and other suitable environmental factors around the habitat. Most of the organisms identified are normal soil organisms, and normal flora of frogs. However, the identification of coliforms indicated faecal contamination, which has public health implications. The pathogens from this source of meat can be transmitted to man both actively and passively, since the frog is used as food or through the process of handling. Spread of infection can be 
prevented by proper cooking, personal hygiene and proper hand washing.

\section{References}

Amuzie, C.C. and Akani, G.C. (2017) Amphibian species in Agbada and Rumuesara, Rivers State: their helminth parasites and culture potentials in the Niger delta. Delta Agriculturist (In press).

Amuzie, C.C. and Aisien, M.S.O. (2017) Effect of anthropogenically induced environmental alterations on lung parasites of amphibians: a preliminary study. Advances in Science and Technology, 11, 6-12.

Baygar, T. and Ozyur, N. (2010) Sensory and chemical changes in smoked frog (Rana esculanta) leg during cold storage. Journal of Animal Vte. Adv. 9(3): 588 - 593.

Barnett, H. L., and Hunter, B. B. (1972) Illustration of Genera of Fungi Imperfecti, 3rd edition, Burgess Publication Co Minneapolis.

Cheesebrough, M. (2000) District Laboratory Practice in Tropical Countries. 2nd Edition, Cambridge University Press, London, UK. Pp 23 -75 .

Chikere, C. B. and Azubuike, C. C. (2014) Culture dependent Characterization of in Biofilms from selected Microhabitats in Rivers State, Nigeria. African Journal of Microbiology Research 8: 1922-1930.

Das, B. S. (2013) Burden of Candida spp. and Aspergillus spp. in pond water in and around South Kolkata. Int Journal of Current Microbiol and applied Sci 2:256-260.

Helfrich, L. A., Neves, R.J. and Parkhurst, J. (2009). Commercial frog farming. Virginia Cooperative Association, 420-255. Www.ext.vt.edu. Retrieved 23rd February, 2017.

Ho, A. L., Gooi, C. T. and Pang, H. K. (2008) Proximate Composition and Fatty acid Profile of Anurans Meat. Journal of Science \& Technology. 22(1): $23-29$.

Holt, J. G., Krieg, N. R. Sneath, P. H. A., Staley, J. T. and Williams, S. T. (1994) Bergey's Manual of Determinative Bacteriology, Williams and
Wilkins, Baltimore, Maryland, USA. pp 151 157.

Larone, D. H. (1995) Medically Important Fungi: A guide to identification. American Society for Microbiology Press, Washington D.C.

Ogbalu, O. K. and Douglas, S. I. (2015) Microbiological Investigation of Selected Flies of Public Health Importance from a Waste Dump Site in Port Harcourt, Nigeria. IOSR Journal of Pharmacy and Biological Sciences 10: 75-78.

Ogbalu, O. K. and Douglas, S. I. (2016) CultureDependent Characterization of Microbes associated with Oil Palm Kernel Borer, Pachymerus cardo in the Niger Delta. Journal Biochem Technol. 8: 14 - 18.

Onadeko, A.B., Egonmwan, R. I. and Saliu, J.K. (2011). Edible Amphibian Species: Local Knowledge of their Consumption in Southwest Nigeria and their Nutritional Value. West African Journal of Applied Ecology, 19, 67-76.

Rodrigues, E., Seixas Filho, J.T., Mello, S.C.R.P., Castagna, A.A., Marcos Aurélio de SOUSA, and Silva, U.P. (2014) Frog meat microbiota (Lithobates catesbeianus) used in infant food Food Sci. Technol, Campinas, 34(1): 51-54.

Oghene, B. O., Oyarekua, M. A. and Edeh, A.N. (2014) Bacteriological status of commonly consumed foods and vegetables from food vendors in a market in Enugu, Nigeria. Int.J.Curr.Microbiol.App.Sci 3(11):151-156.

Okechalu, J. N. Dashen, M. M. and Lari PM (2011) Microbiological quality and chemical characteristics of palm oil sold within Jos Metropolis, Plateau State, Nigeria. Journal of Microbiol Biotech Res 1: 107-112.

Okogbenin, O. B. Okogbenin, E. A. Okunwaye T, and Odigie (2014) Isolation of food pathogens from freshly milled palm oil and the effect of sterilization on oil quality parameters. Journal of Food Security 2: 65-71.

Sichewo, P. R. Robert, K. G., John, M. and Willard, M. (2014) Isolation and identification of pathogenic bacteria in edible fish: A case study of rural aquaculture projects feeding livestock manure to fish in Zimbabwe. Int.J.Curr.Microbiol.App.Sci 3(11): 897-904.

\section{How to cite this article:}

Douglas, Salome Ibietela and Amuzie, C.C. 2017. Microbiological Quality of Hoplobatrachus occipitalis (Amphibia, Anura) Used as Meat. Int.J.Curr.Microbiol.App.Sci. 6(6): 3192-3200.

doi: https://doi.org/10.20546/ijcmas.2017.606.376 